\title{
STUDYING SEA WATERWAY SYSTEM WITH THE AID OF COMPUTER SIMULATION METHODS
}

\author{
Stanisław Gucma, Prof. \\ Maritime University of Szczecin, Poland
}

\begin{abstract}
The article presents a systematic approach to studying sea waterways. Relations between the parameters of sea waterway system elements and the conditions of safe ship operation are determined. Principles of formulation of the simulation experiment research process in the sea waterway system design process at the preliminary and detailed design stages are defined.
\end{abstract}

Keywords: Sea waterway systems, Sea traffic engineering, Simulation methods in waterway system studies

\section{INTRODUCTION}

The sea waterway is to be adapted is such a way as to enable the navigation of specific types of watercraft units characterised by a given length, width, draught, and height. The basic condition of navigation on sea waterways is the safety of navigation, meant as the safety of the ship and its environment when performing manoeuvres in certain water regions, in the aspect of a possible navigation accident (an undesired event bringing damages and losses) [4].

Designing sea waterways refers to non-existing systems. In those situations experimental investigations of real systems is substituted by studying their models with the aid of mathematical modelling and computer simulation methods.

Mathematical modelling refers to relations between the examined real system and its model. It is oriented on describing the reality in the language of mathematics and formal logics, and consists in creating the structure of the model and identifying its parameters. Modelling will only meet the compatibility criterion when the initial assumptions are rational, i.e. they are correct and sufficiently accurate from the point of view of the assumed goal. Even correct application of the complicated mathematical apparatus to modelling will fail to meet the compatibility criterion when the initial assumptions of the model are based on false hypotheses. Therefore research worker's attention should mainly focus on the stages of task formulation and designing the simulation experiment system. The compatibility criterion cannon be met without deep intuition, experience, and understanding of the phenomenon to be examined, and without precise formulation of the task to be solved [6].
Computer simulation refers to relations between the mathematical model of the examined system and the computer (computer simulator) on which simulation calculations are performed. It mainly consists in creating the simulation model and performing simulation analyses [1]. The computer simulation is a method of experimental examination of system models, which bases on repeated tests to obtain reliable results describing particular states of the examined model. The computer simulation includes all actions oriented on creating the simulation model and performing tests on this model. Simulation methods are at present very frequently used in studying sea traffic engineering issues, due to [4]:

- universal nature of the studies which enable to obtain results of different accuracy, depending on problem formulation. This accuracy is mainly determined by the use of the simulation model of certain complexity level;

- relatively low cost of the studies.

Taking into account full availability of different types of manoeuvring simulators used for didactic purposes, various "experiments" are performed which have nothing in common with the simulation studies. Even a contemporary manoeuvring simulator with $3 \mathrm{D}$ projection type visualisation and verified model of the vessel will fail to meet the basic criterion of compatibility of the examined system with the model when one stage of the simulation study is poorly conducted (or not conducted at all).

This refers most of all to such stages of simulation studies as:

- formulating the research problem,

- designing the experimental system,

- $\quad$ statistical analysis of the results of the simulation study. 
Erroneous or inaccurate assumptions adopted at the stage of research problem formulation or experimental system design will not lead to meeting the compatibility criterion even if the model of ship motion has been positively verified. Similarly, the lack of special statistical methods of processing of the obtained results will not enable to reach the compatibility criterion between the model and the real system as well.

Systematic approach to studying sea waterways provides opportunities for optimisation of parameters of three basic system elements, which are [2]:

- waterway,

- navigation,

- traffic control.

Mathematical description of the conditions of safe ship operation on the examined waterway enables to define mutual relations between these conditions and the sea waterway system elements. The above relations enable, in turn, to formulate precisely the research problem of the sea waterway system simulation study and to avoid mistakes resulting from the lack of experience of the research worker.

\section{SEA WATERWAY SYSTEMS}

One of criteria which is more and more frequently used in the world to evaluate the safety of navigation is the navigation risk [PIANC 2014]. The navigation risk on the i-th waterway segment can be expressed as the function [5]:

$$
\mathrm{R}_{\mathrm{i}}=f\left(\mathrm{~A}_{\mathrm{i}}, \mathrm{S}_{\mathrm{i}}, \mathrm{N}_{\mathrm{i}}, \mathrm{H}_{\mathrm{i}}, \mathrm{M}_{\mathrm{i}}, \mathrm{I}_{\mathrm{i}}, \mathrm{Z}_{\mathrm{i}}\right)
$$

where:

$\mathrm{R}_{\mathrm{i}}$ - navigation risk on the $\mathrm{i}$-th waterway segment,

$\mathrm{A}_{\mathrm{i}}$ - parameters of the water region,

$\mathrm{S}_{i}$ - parameters of the ship,

$\mathrm{N}_{\mathrm{i}}$ - parameters of the positioning systems,

$\mathrm{H}_{\mathrm{i}}$ - hydrometeorological parameters,

$\mathrm{M}_{\mathrm{i}}$ - parameters of the performed manoeuvre,

$I_{i}$ - traffic parameters,

$\mathrm{Z}_{\mathrm{i}}$ - parameters of the traffic control system.

The navigation safety function (navigation risk) $\mathrm{R}_{\mathrm{i}}$ is the variable which depends on the independent variables $\mathrm{Ai}, \mathrm{S}_{\mathrm{i}}$, $\mathrm{N}_{\mathrm{i}}, \mathrm{H}_{\mathrm{i}}, \mathrm{M}_{\mathrm{i}}, \mathrm{I}_{\mathrm{i}}, \mathrm{Z}_{\mathrm{i}}$, defined by a number of factors describing the system consisting of the: ship - water region - positioning system - current hydrometeorological conditions - traffic intensity - traffic control system - manoeuvring tactics.

Each sea waterway has constraints to be obeyed by ships navigating on this waterway. These constraints bear the name of conditions of sea waterway exploitation, or conditions of ship operation on sea waterway, and refer to:

- $\quad$ parameters of ships navigating on the waterway;

- hydrometeorological conditions at which certain types of ships can use the waterway;

- $\quad$ parameters of waterway traffic and throughput;

- $\quad$ conditions for manoeuvres to be performed by ships on the waterway.
Taking into account the above constraints having the form of sea waterway exploitation conditions, the navigation risk on the i-th waterway segment for a given ship performing a given manoeuvre in given hydrometeorological conditions can be presented as the simplified function:

$$
\mathrm{R}_{\mathrm{i}}=f\left(\mathrm{~A}_{\mathrm{i}}, \mathrm{N}_{\mathrm{i}}, \mathrm{Z}_{\mathrm{i}}\right)
$$

The sea waterway system in the sea traffic engineering approach consists of a series of separate line segments (n). Each waterway segment consists, in turn, of three basic elements [3]:

1. Waterway subsystem.

2. Ship positioning subsystem (navigation subsystem).

3. Traffic control subsystem.

The above elements interact with each other and remarkably affect the characteristics of the system.

Consecutive waterway segments are selected using the following comparison criteria:

- performed manoeuvre,

- technical parameters of the waterway,

- technical parameters of the used navigation systems,

- current hydrometeorological conditions,

- harbour regulations and traffic control systems.

Particular waterway segments are defined in such a way that identical comparison criteria are valid along the entire length of the given segment.

Performing an assumed (planned) manoeuvre by the ship of certain parameters is a function of the waterway system. The input parameter here is the planned manoeuvre, while the output parameter is the real manoeuvre performed by the ship. Sea traffic engineering makes use of cybernetic definition of a system [4]. They are relatively isolated systems, in which the distinct entity is coupled with the environment via input and output parameters [6]. The waterway system is built at human assistance and the boundaries between the system and its model are blurred. A general model of the waterway system is given in Fig. 1.

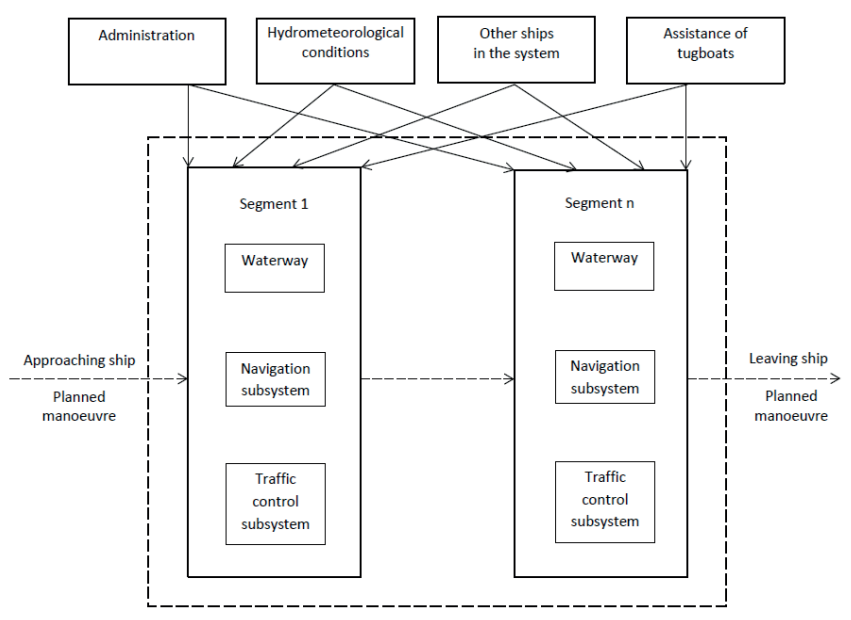

Fig. 1. General model of the waterway system with $n$ segments 
The sea waterway system is defined by parameters of its elements (subsystems). Three elements of the sea waterway system which are defined on its particular segments are the functions of safe ship operation conditions, therefore the i-th sea waterway segment can be given in the matrix form in the following way [3]:

$$
\left[\begin{array}{c}
\mathbf{A}_{\mathbf{i}} \\
\mathbf{N}_{\text {in }} \\
\mathbf{Z}_{\text {im }}
\end{array}\right]=\boldsymbol{f}\left(W_{i}\right)
$$

where:

$\mathrm{W}_{\mathrm{i}}$ - conditions of safe ship operation on the waterway.

When describing consecutive elements of the system, the following matrix forms were used for the i-th waterway segment:

- Waterway subsystem:

$$
\mathbf{A}_{\mathbf{i}}=\left[\begin{array}{l}
t_{i} \\
l_{i} \\
D_{i} \\
h_{i}
\end{array}\right]
$$

where:

$t_{i}$ - type of the $\mathrm{i}$-th waterway segment;

$1_{i}$ - length of the i-th waterway segment;

$\mathrm{D}_{\mathrm{i}}$ - width of the available water region of the $\mathrm{i}$-th waterway segment;

$h_{i}-$ minimal depth of the $\mathrm{i}$-th waterway segment.

From the point of view of sea traffic engineering, the following types of waterways can be named:

- water lane:

- rectilinear segment,

- winding;

- harbour entrance (rectilinear, or having a form of winding or a number of windings);

- anchorage;

- harbour basin;

- sea lock.

- Navigation subsystem:

$$
\mathbf{N}_{\text {in }}=\left[\begin{array}{l}
d_{i n} \\
m_{i n} \\
n_{i n}
\end{array}\right]
$$

where:

$\mathrm{d}_{\mathrm{in}}-$ accuracy of the $\mathrm{n}$-th navigation system on the i-th waterway segment (standard deviation);

$\mathrm{m}_{\text {in }}$ - availability of the $\mathrm{n}$-th navigation system on the i-th waterway segment (depending on the time of day and visibility);

$\mathrm{n}_{\mathrm{in}}$ - reliability of the $\mathrm{n}$-th navigation system on the i-th waterway segment (technical reliability).
Positioning systems used on waterways can be divided into:

- terrestrial (making use of optical or radar navigation);

- satellite systems (making use of satellite navigation and electronic map technology).

- Traffic control subsystem:

$$
\mathbf{Z}_{\mathbf{i m}}=\left[\begin{array}{l}
r_{i m} \\
\boldsymbol{o}_{i m}
\end{array}\right]
$$

where:

$\mathrm{r}_{\mathrm{im}}$ - type of the m-th traffic control system on the i-th waterway segment;

$o_{i m}$ - type of the m-th system of hydrometeorological information (hydrometeorological assistance) on the i-th waterway segment.

The following four types of traffic control and hydrometeorological assistance systems can be named:

1. Lack of traffic control and hydrometeorological information systems (no VTS - Wessel Traffic System).

2. VTS provides information service.

General information on current conditions on the waterway.

3. VTS provides ship traffic arrangement service.

Information about current hydrometeorological conditions on each waterline segment.

4. VTS provides navigation assistance service.

The operating system of dynamic keel clearance evaluation.

\section{CONDITIONS OF SAFE SHIP OPERATION ON SEA WATERWAY}

The conditions of safe ship operation on sea waterway are described by the vector of safe operation of the "maximal ship" on the i-th line segment of the examined waterline, written as:

$$
\mathbf{W}_{\mathbf{i}}=\left[t_{y p}, L_{c}, B, T, H_{s t}, V, C, \mathbf{H}_{\mathbf{i}}\right]
$$

where:

$\mathrm{t}_{\mathrm{yp}}$ - type of the "maximal ship";

$\mathrm{L}_{\mathrm{c}}^{\mathrm{yp}}$ - overall length of the "maximal ship";

B - width of the "maximal ship";

$\mathrm{T}$ - draught of the "maximal ship";

$\mathrm{H}_{\text {st }}$ - height of the "maximal ship" from the water level to the masthead

$\mathrm{V}_{\mathrm{i}}$ - permissible speed of the "maximal ship" on the i-th waterway segment;

$\mathrm{C}_{\mathrm{i}}$ - tugboat assistance on the $\mathrm{i}$-th waterway segment (the required number and tow-rope forces of tugboats);

$\mathrm{H}_{\mathrm{i}}$ - vector of hydrometeorological conditions defined as permissible for the "maximal ship" on the i-th waterway segment. 


$$
\mathbf{H}_{\mathbf{i}}=\left[d / n, \Delta h_{i}, V_{w i}, K R_{w i}, V_{p i}, h_{f i}, K R_{f i}\right]
$$

where:

$\mathrm{d} / \mathrm{n}$ - permissible time of day (in daylight or without limits);

$\Delta$ hi - permissible drop of the water table level;

$\mathrm{V}_{\mathrm{wi}}-$ permissible wind speed on the $\mathrm{i}$-th line segment;

$\mathrm{KR}_{\mathrm{wi}}-$ wind direction limits (if defined for the i-th line segment);

$\mathrm{V}_{\mathrm{pi}}$ - permissible sea current speed on the $\mathrm{i}$-th line segment;

$h_{f i}$ - permissible wave height on the i-th line segment; $\mathrm{KR}_{\mathrm{fi}}-$ wave approach direction limits (if defined).

The vector of safe operation of the "maximal ship" on the i-th waterline segment defines clearly the keel clearance $(\Delta)$ and the width (d) of the safe manoeuvring area of the "maximal ship". Hence:

$$
\begin{aligned}
& \Delta_{i}=f_{1}\left(\mathbf{W}_{\mathbf{i}}\right) \\
& d_{i}=f_{2}\left(\mathbf{W}_{\mathbf{i}}\right)
\end{aligned}
$$

Taking into account, in turn, the basic navigation safety condition (12) we can define the functional relation:

$$
\left[\begin{array}{l}
\mathbf{A}_{\mathbf{i}} \\
\mathbf{N}_{\mathbf{i}} \\
\mathbf{Z}_{\mathbf{i}}
\end{array}\right]=\boldsymbol{f}_{n}\left(\Delta_{i}, d_{i}\right)
$$

Mutual relations between the parameters of sea waterway systems and the conditions of safe ship operation on a given waterway impose two reciprocal tasks:

1. Determining parameters of basic elements of the constructed or reconstructed sea waterway system (waterway, navigation subsystem, traffic control subsystem). The parameters of the sea waterway system are functions of the designed (assumed) conditions of safe ship operation (vector of safe ship operation conditions):

$$
\left[\begin{array}{c}
\mathbf{A}_{\mathbf{i}} \\
\mathbf{N}_{\text {in }} \\
\mathbf{Z}_{\text {im }}
\end{array}\right]=f\left(\mathbf{W}_{\mathbf{i}}\right)
$$

2. Determining conditions of safe ship operation in the existing sea waterway system with known parameters. That means that the state vector of safe ship operation conditions is a function of parameters of the sea waterway system:

$$
\mathbf{W}_{\mathbf{i}}=\mathbf{F}\left[\begin{array}{c}
\mathbf{A}_{\mathbf{i}} \\
\mathbf{N}_{\text {in }} \\
\mathbf{Z}_{\text {im }}
\end{array}\right]
$$

A basic problem here refers to identification of the vector of safe operation of the "maximal ships" on the examined waterway (system). In each task this vector is identified in another way.

\section{SIMULATION STUDIES OF SEA WATERWAY SYSTEMS}

Computer simulation methods are used at the stage of detailed sea waterway system design. These methods bring precise description of safe manoeuvring areas for ships which are presently in operation or those planned for future operation, i.e. determine, at the assumed confidence level , the width of the safe manoeuvring area accepted for operation of the "maximal ships" of certain types on particular waterway segments in the conditions which are permissible for those ships.

The basic navigation safety condition:

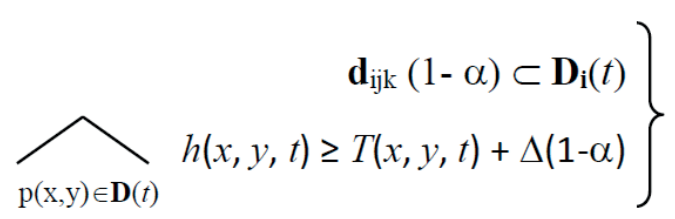

where:

$$
\begin{aligned}
& \mathrm{D}_{\mathrm{i}}(\mathrm{t}) \text { - available navigation area of the } \mathrm{i} \text {-th waterway } \\
& \text { segment (which meets the safe depth } \\
& \text { condition at time } \mathrm{t}) \text {; } \\
& \mathrm{d}_{\mathrm{ijk}}(1-\sigma) \text { - safe manoeuvring area of the } \mathrm{j} \text {-th ship } \\
& \text { performingthemanoeuvreonthei-thwaterway } \\
& \text { segment in the k-th navigation conditions, } \\
& \text { determined at the confidence level 1- } \alpha \text {; }
\end{aligned}
$$

$\mathrm{h}(\mathrm{x}, \mathrm{y}, \mathrm{t})$ - water region depth at point $(\mathrm{x}, \mathrm{y})$ and time $\mathrm{t}$; $\mathrm{T}(\mathrm{x}, \mathrm{y}, \mathrm{t})$ - draught of the "maximal ship";

$\Delta(1-\alpha)$ - keel clearance determined at the confidence level 1- $\alpha$;

makes the basis for determining the available navigation area $D_{i}(t)$ of the waterway as the set of maximal available widths on (i) successive waterway segments.

The simulation study procedure applied when designing sea waterway systems comprises the following stages:

- formulating the research problem, including the goal of the design, the applied simulation methods, and the type of simulator;

- creating or selecting ship motion models on the selected simulator, with their further verification;

- designing an experimental system and performing the experiment;

- processing the obtained results and performing their statistical analysis.

Formulating the research problem of the simulation experiment in the sea waterway design process consists in:

- determining the goal of the research;

- determining the confidence level and the accepted risk of the safe manoeuvring area;

- $\quad$ selecting the simulation method;

- $\quad$ selecting the type of the manoeuvring simulator. 
In the simulation studies used at the stage of detailed sea waterway design, use is made of the results of preliminary waterway design to determine:

- parameters of basic waterway system elements which were determined using empirical methods at the preliminary design stage:

$$
\left[\begin{array}{l}
\mathbf{A}_{\mathbf{i}} \\
\mathbf{N}_{\mathbf{i}} \\
\mathbf{Z}_{\mathbf{i}}
\end{array}\right]
$$

- the verified matrix of conditions of safe ship operation on the designed waterway $\mathrm{M}_{\mathrm{i}}$ :

$$
\mathbf{M}_{\mathbf{i}}=\left[\begin{array}{cccccccc}
t_{y p 1}, & L_{c 1}, & B_{1}, & T_{1}, & H_{s t 1}, & V_{i 1}, & C_{i 1}, & \mathbf{H}_{\mathbf{i} 1} \\
\ldots & \ldots & \ldots & \ldots & \ldots & \ldots & \ldots & \ldots \\
t_{y p j}, & L_{c j}, & B_{j}, & T_{j}, & H_{s t j}, & V_{i j}, & C_{i j}, & \mathbf{H}_{\mathrm{ij}}
\end{array}\right]=\left[\begin{array}{c}
\mathbf{W}_{\mathbf{i} 1} \\
\ldots \\
\mathbf{W}_{\mathbf{i j}}
\end{array}\right]
$$

where:

$\mathrm{W}_{\mathrm{ij}}$ - vector of safe operation conditions for the "maximal ship" of $\mathrm{j}$-th type in operation on the examined waterway.

- the vector of safe operation conditions for the "maximal ship" which requires the largest width $\mathrm{d}_{\mathrm{i} \max }$ of the save manoeuvring area and which was used at the preliminary stage for determining the parameters of the waterway elements:

$$
\mathbf{W}_{\mathrm{i} \max }=\left[t_{y p}, L_{c}, B, T, H_{s t}, V, C, \mathbf{H}_{\mathbf{i}}\right]
$$

If the comparable widths of the safe manoeuvring areas were calculated for more "maximal ships" than one at the preliminary design stage, all these ships are qualified for the simulation study. A case can occur when the simulation study is performed for a number of models having the following safe operation vectors:

$$
\begin{aligned}
& \mathbf{W}_{\mathbf{i}}\left(L_{c}=\max \right) \\
& \mathbf{W}_{\mathbf{i}}(B=\max ) \\
& \mathbf{W}_{\mathbf{i}}(T=\max )
\end{aligned}
$$

The "maximal ships" which were qualified for the simulation study bear the name of "characteristic ships" of the examined waterway. The above data is used for selecting the method of simulation study and the type of the used simulators.

At present, the following computer simulation methods are used at the waterway design stage:

1. Method RTS (Real Time Simulation) of ship motion which makes use of non-autonomous models.

2. Method FTS (Fast Time Simulation) of ship motion which makes use of autonomous models.

3. Method which generalises the results of simulation studies.
At the detailed design stage, the simulation methods no. 1 and 2 are used, namely:

1. Simulation making use of non-autonomous models (Fig. 2).

2. Simulation making use of autonomous models (Fig.3).

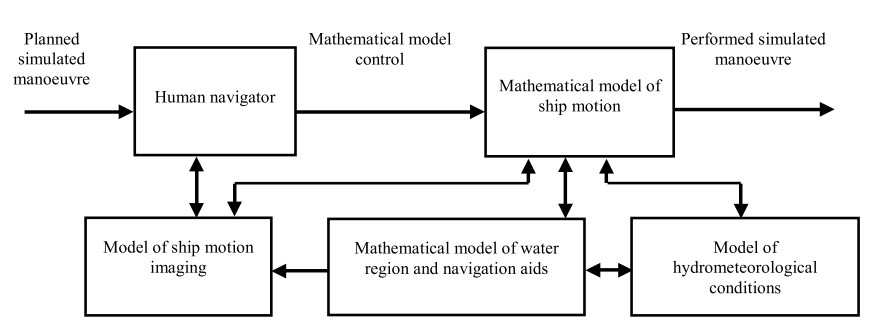

Fig. 2. Non-autonomous simulation model of ship motion on confined water regions

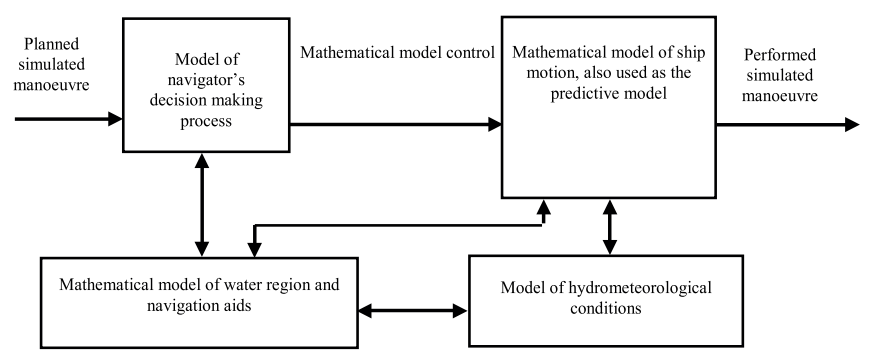

Fig. 3. Autonomous simulation model of ship motion on confined water regions

In the non-autonomous simulation models the ship motion is controlled by a human navigator, while in the autonomous models it is controlled by the mathematical model of navigator. Advantages and limitations of these two methods and their possible applications are given in Table 1.

Tab. 1. Comparing simulation methods used at the stage of detailed sea waterway design

\begin{tabular}{|c|c|c|c|c|}
\hline $\begin{array}{c}\text { Simulation } \\
\text { method }\end{array}$ & Applied methods & Advantages & Limitations & Possible applications \\
\hline $\begin{array}{c}\text { Real Time } \\
\text { Simulation }\end{array}$ & $\begin{array}{c}\text { Non-autonomous } \\
\text { model of ship motion }\end{array}$ & $\begin{array}{c}\text { Good results of } \\
\text { verification, also at } \\
\text { complicated manoeurres. } \\
\text { Allows human } \\
\text { qualifications to be taken } \\
\text { into account. Allows } \\
\text { training courses to be } \\
\text { conducted }\end{array}$ & $\begin{array}{c}\text { Time consuming and } \\
\text { relatively expensive studies }\end{array}$ & $\begin{array}{c}\text { For different types of } \\
\text { waterways, as well as for } \\
\text { different ships, } \\
\text { manoeuvres, and } \\
\text { navigation conditions }\end{array}$ \\
\hline $\begin{array}{c}\text { Fast Time } \\
\text { Simulation }\end{array}$ & $\begin{array}{c}\text { Autonomous model } \\
\text { of ship motion }\end{array}$ & $\begin{array}{c}\text { Fast and relatively cheap } \\
\text { study, allow a large number } \\
\text { of cases to be studied in } \\
\text { one session (high number } \\
\text { of repeats) }\end{array}$ & $\begin{array}{c}\text { The algorithm of human } \\
\text { decision making limits the } \\
\text { application of the method } \\
\text { in complicated } \\
\text { manoeurres. Good } \\
\text { verification results obtained } \\
\text { only on rectlinear } \\
\text { waterway segments and } \\
\text { windings }\end{array}$ & $\begin{array}{c}\text { For rectilinear waterway } \\
\text { segments and windings }\end{array}$ \\
\hline
\end{tabular}

\section{CONCLUSIONS}

The article presents a new systematic approach to studying sea waterways with the aid of computer simulation methods. Models of the sea waterway system and its elements are defined, along with parameters of those elements. 
Systematic approach to sea waterway studies makes it possible to optimise three basic elements of the system, which are:

- waterway,

- navigation,

- traffic control.

Conditions of safe ship operation in the sea waterway system are described. Relations between the system elements and the conditions of safe ship operation in this system are defined. Based on these relations, principles of clear formulation of research problems in simulation studies of sea waterways are worked out.

The simulation studies are used at the stage of detailed sea waterway system design. Correct formulation of their research problem, followed by proper design of the experimental system and processing of the obtained results, is of high importance, as it enables to obtain reliable results and avoid errors in designing sea waterway systems.

The here described method of simulation studies of sea waterway systems was used in re-designing the waterway to the Swinoujście harbour, which was modernised to take into account requirements of LNG carriers of Q-flex type, and in modernisation of the Świnoujście-Szczecin waterway (depth increase to $12,5 \mathrm{~m}$ ).

\section{BIBLIOGRAPHY}

1. Gucma M. (2007): Multi-factor Variance Analysis Method for Optimization of Pilot System Interface. Proceeding of the XII International Scientific and Technical Conference on Marine Traffic Engineering. Świnoujście, 20-23.11.2007.

2. Gucma S. (2013a): Optimisation of sea waterway system parameters in marine traffic engineering. Journal of KONBIN, No 2 (26) 2013, Wydawnictwo ITWL, Warszawa.

3. Gucma S. (2013b): Conditions of safe ship operation in sea waterway systems (in Polish). Proc. of the International Scientific Conference on "Sea Traffic Engineering". Świnoujście, 16-18.10.2013.

4. Gucma S., Gucma L., Zalewski P. (2008): Simulation methods in sea traffic engineering (in Polish). Wydawnictwo Naukowe Akademii Morskiej w Szczecinie, Szczecin 2008.

5. Gucma S., Ślączka W., Zalewski P. (2013): Parameters of water lanes and navigation systems determined with the aid of navigation safety criterion (in Polish). Wydawnictwo Naukowe Akademii Morskiej w Szczecinie, Szczecin 2013.

6. Gutenbaum J. (2003): Mathematical modelling of systems (in Polish). Akademicka Oficyna Wydawnicza EXIT, Warszawa 2003.

7. PIANC (2014): Report No 121-2014. Harbour approach channels design guidelines. PIANC Secrétariat Général, Bruxelles.

\title{
CONTACT WITH THE AUTOR
}

\author{
Stanisław Gucma \\ Marine Traffic Engineering Centre \\ Faculty of Navigation \\ Maritime University of Szczecin \\ 1-2 Waly Chrobrego Str. \\ 70-500 Szczecin \\ POLAND \\ e-mail: s.gucma@am.szczecin.pl
}

